Check for updates

Cite this: RSC Adv., 2017, 7, 47954

Received 18th July 2017

Accepted 24th September 2017

DOI: $10.1039 / c 7 r a 07905 b$

rsc.li/rsc-advances

\section{Analysis of the microscopic mechanism of coal wettability evolution in different metamorphic states based on NMR and XPS experiments}

\begin{abstract}
Cuicui Xu, ab Gang Zhou*ab and Han Qiu (D) ab
To investigate the evolution of carbon- and oxygen-containing groups during metamorphism and the influence of the structural variation of coal on its wettability, NMR and XPS were employed to study the two main elements, carbon and oxygen, in coal dust. Our results show that with an increase of the metamorphic degree, the number of highly reactive hydroxyl and carboxyl groups show a descending trend whereas the number of low reactivity ether and carbonyl groups increases. The number of carboncontaining groups gradually increases when the metamorphic degree increases, due to a clustering change process which includes an increase in the number of aromatic carbons (Ar- $\mathrm{C}, \mathrm{H}$ ) and a simultaneous decrease in the number of carboxyl carbons $(-\mathrm{COOH})$, methylene carbons $\left(\mathrm{CH}_{2}\right)$ and ether based carbons ( $\mathrm{Ar}-\mathrm{O}, \mathrm{R}-\mathrm{O})$. The reduction rate of carboxyl carbon $(-\mathrm{COOH})$ is closest to the growth rate of aromatic carbon ( $\mathrm{Ar}-\mathrm{C}, \mathrm{H})$. The methyl $\left(\mathrm{CH}_{3}\right)$ and carboxyl $(\mathrm{C}=\mathrm{O})$ carbon evolve discontinuously with the metamorphic degree, which is different from the other carbon groups. Linearregression analysis suggests that the correlation coefficients between aromatic ( $\mathrm{Ar}-\mathrm{C}, \mathrm{H})$, ether $(\mathrm{R}-\mathrm{O})$, methylene $\left(\mathrm{CH}_{2}\right)$ and carboxyl $(-\mathrm{COOH})$ carbons and wettability are 0.98, 0.97, 0.96 and 0.92 , respectively, indicating that the main contribution to the wettability from carbon-containing groups comes from these groups. In contrast, hydroxyl oxygen $(-\mathrm{OH})$ has a correlation coefficient as high as 0.98 , and is a major contributor from the oxygen-containing groups.
\end{abstract}

\section{Introduction}

Wettability is one of the most important chemical properties of coal dust. It has very wide applications in areas including coal mine safety, mineral processing, coal chemistry and organic materials. In particular, the importance of wettability is exceptionally prominent in the prevention and control of coal mine dust, ${ }^{1}$ since coal dust brings hazards in the following four aspects: (1) long-term dust-exposed personnel are susceptible to pneumoconiosis; (2) under certain conditions, dust explosion accidents might occur; (3) coal dust lowers the visibility of the working site, and thus can easily cause other accidents; (4) coal dust speeds up the wearing of electromechanical equipment and the deterioration of the reliability of precise instruments..$^{2-5}$ Currently, worldwide dust prevention technologies primarily include coal seam water infusion, spraying dust-settling and chemical dust suppression. ${ }^{6,7}$ Although these methods reduce the dust concentration on the working face to some extent, their

\footnotetext{
${ }^{a}$ State Key Laboratory of Mining Disaster Prevention and Control Co-founded by Shandong Province and the Ministry of Science and Technology, Shandong University of Science and Technology, Qingdao 266590, China. E-mail: zhougang@ sdust.edu.cn

${ }^{b}$ College of Mining and Safety Engineering, Shandong University of Science and Technology, Qingdao 266590, China
}

removal rates of respirable dust are still extremely low. This is mainly because current dust removal technologies have not taken the physical and chemical properties (especially the wetting property) of coal dust into consideration. The wettability of coal dust is the theoretical foundation of the suppression of dust using wet methods and is the major reference factor in designing and developing chemical dust suppressors.

For a long time, research on the wettability of coal dust has been restricted to its accurate measurement and macroscopic characterization. By applying methods like sedimentation and thin film flotation to determine the wettability variance of coal dust $^{8}$ the relative wettability of various coal dusts can be observed directly. However, the errors are large. T. Young et al. ${ }^{9}$ for the first time, proposed the concept of the contact angle to describe the solid-liquid-gas interface system and thus quantified the wetting phenomenon and utilized droplet shape analysis to calculate the contact angle between coal dust and liquid. This method quantitatively described the complexity of coal dust wetting and was widely applied to determine coal dust wettability. At the end of last century, researchers from different countries carried out a series of experiments to explore the influence of structural differences on the wettability of coal dust and elaborated on the structural factors affecting the differences in coal dust wettability. Russell J. Crawford et al. ${ }^{10}$ studied the influence of a series of coal ranks and mineral compositions 
of coals with different metamorphic degrees on the contact angle. They concluded that the hydrophobicity of the coal surface mainly relies on the ratio of carbon to oxygen (or the coal grade). D. V. Keller et al. ${ }^{\mathbf{1 1}}$ studied the contact angle of water on coal dust and pointed out that the major factors influencing the contact angle were the carbon and mineral content in the coal and the state of surface oxidation. Moreover, J. A. GutierrezRodriguez et al. ${ }^{12}$ found that the hydrophobicity of coal dust decreased with the decrease of the coal rank, fixed carbon content and total carbon content. Meanwhile, the hydrophobicity also decreased with an increase in the oxygen and hydroxyl content. The coal surfaces fell into three states: strong hydrophobicity, weak hydrophobicity and hydrophilicity. These researchers performed a preliminary exploration of the wetting mechanism for coal dust from the microscopic point of view. However, restricted by past technology, these conclusions obtained could only roughly reveal the major factors that influence coal wetting. The theory of coal wetting still needs to be supplemented and improved.

In recent years, with the development of modern science and technology, researchers have started to extensively apply advanced and reliable analytical techniques combined with computer analysis techniques to perform in-depth studies of the microstructures of coal and coal products. Arunima Sarkar and Duygu Kocaefe ${ }^{\mathbf{1 3}}$ utilized Fourier transform infrared (FTIR) spectroscopy and X-ray photoelectron spectroscopy (XPS) to analyze the microstructure of coke/pitch and discovered that oxygen- and nitrogen-containing functional groups had relatively positive effects on the wettability of coke/pitch. H. Guo and A. Kantzas ${ }^{\mathbf{1 4}}$ applied low field Nuclear Magnetic Resonance (LF-NMR) to measure the wettability of coal samples of different dimensions and studied the influence of $\mathrm{CO}_{2}$ in coals on the wettability of coal samples. H. Chang et al. ${ }^{15}$ adopted an electrophoretic technique to analyze the wetting relationship between a series of cationic and zwitterionic surfactants and coal pitch. It is concluded that this kind of wetting behavior results from both electrostatic interactions and van der Waals adsorption.

Although the above researchers used instrumental analysis methods to describe in detail the factors that influence the wettability of coal and coal products in terms of nitrogen/ oxygen-containing functional groups, the dimensions of coal samples, the $\mathrm{CO}_{2}$ content in coal and electrostatic interactions, ${ }^{16-19}$ studies concerning relationships between the carbon chain structure on the surface of coal dust, carbon/oxygencontaining functional groups in coals and wettability still lack specificity.

To address this problem, we selected six kinds of coal dust with different metamorphic degrees as examples and used $\mathrm{NMR}^{20,21}$ to obtain the distribution of carbon in the molecular structure of coal dust. At the same time, using XPS, ${ }^{22,23}$ the binding status of the carbon and oxygen on the surface of the coal dust was obtained and quantitative information regarding hydrophilic groups like carboxyl and hydroxyl groups was clarified. Finally, the influence of the carbon structure and the surface carbon/oxygen-containing functional groups on the wettability of coal dust was analyzed. Therefore, the wettability of coal dust with different metamorphic degrees was microscopically explained from the molecular structure, which will enrich and improve the existing understanding of the coal dust wetting mechanism and will provide ideas for developing novel dust suppressors.

\section{Experimental methods and processes}

\subsection{Selection of samples}

There is an extremely close relationship between coal properties and the metamorphic degree and many coals regularly change from lignite to bitumite and later to anthracite. To ensure the representativeness of the coal samples, six coal samples with different coal ranks were selected as the experimental samples as listed in Table 1.

Industrial analysis and element analysis reveal the properties of coal from different aspects and can be regarded as the references for coal characteristics. Industrial and elemental analysis of coal dust was performed according to the National Standards GB/T212-2008 and GB/T212-2001. The results are shown in Table 2.

From Table 2 it is clear that: (1) for industrial analytical indicators, with the increase in metamorphic degree, the most prominent result is that the carbon content increases and the oxygen content decreases. There are certain variations in water content, ash content and volatile components in different types of coal. However, these differences are not significantly correlated to the metamorphic degree. In contrast, the coal formation environment has a relatively large influence on these differences: (2) regarding the elemental analysis indicator, with the increase in metamorphic degree, the most apparent changes are the increase in carbon content as well as the decrease in oxygen content. Variation of nitrogen and sulphur with changes in metamorphic degree is not evident.

\subsection{The NMR experiment}

The experiments were carried out using a BRUKER AVANCE III $500 \mathrm{M}$ solid nuclear magnetic resonance (NMR) spectrometer and a $4 \mathrm{~mm}$ solid $\mathrm{H}-\mathrm{X}-\mathrm{Y}$ triple-resonance probe was used. The dried coal dust samples were placed into $\mathrm{ZrO}_{2}$ sampling tubes for future measurement. The test conditions were: a revolution speed of $5 \mathrm{kHz}$, the resonant frequency of a ${ }^{13} \mathrm{C}$ nucleus of $100.38 \mathrm{MHz}$, a sampling time of $0.0026 \mathrm{~s}$, a delay time of $2 \mathrm{~s}$ and a scanning number of $10240-20480$. The cross-polarization (CP) and Total Suppression of Sidebands (TOSS) techniques were applied. The contact period was $3000 \mu$ s and the spectrum width was $39.682 \mathrm{~Hz}$. To avoid the mineral materials affecting the test results, samples were treated using a deliming process to suppress the ash content below 1\%. In order to comprehensively understand the information of the carbon skeleton, NUTS 98 software was utilized to fit and integrate the ${ }^{13} \mathrm{C} \mathrm{CP} /$ MAS NMR spectra of all the test samples, as seen in Fig. 1. 
Table 1 Coal samples

\begin{tabular}{lll}
\hline Coal type & Sample point & Station \\
\hline Lignite & 4301 working face of Beizao coal & Longkou, Shandong \\
Long flame coal & 12207 working face of Shangwan coal & Ordos, Inner Mongolia \\
Gas coal & 20102 working face of Yushuwan coal & Yulin, Shanxi \\
Fat coal & $1301 \mathrm{~N}$ working face of Xinjulong coal & Heze, Shandong \\
Coking coal & 1013 working face of Wugou coal & Huaibei, Anhui \\
Anthracite & 8124 working face of Yangquan coal & Yangquan, Shanxi
\end{tabular}

\subsection{The XPS experiment}

The XPS experimental analysis of coal dust was carried out using a Thermo Scientific ESCALAB250Xi multifunctional X-ray photoelectron spectrometer. The detailed experimental conditions were: an excitation source of monochromatic $\mathrm{Al} \mathrm{K} \alpha \mathrm{X}$-rays with a power around $200 \mathrm{~W}$. A beam of $500 \mu \mathrm{m}$ in diameter was used and the sample was purged in a vacuum of $3 \times 10^{-10}$ mbar. The electron binding energy was corrected using the $\mathrm{C} 1 \mathrm{~s}$ peak $(284.6 \mathrm{eV})$ for the contaminated carbon. To analyze the functional groups on the surface of the coal dust, the carbon elemental peaks that required analysis were scanned with high resolution in narrow regions to obtain more accurate information. By peak fitting and related calculation, the types and ratio of the carbon-containing functional groups can be determined. The XPS spectra of the samples are shown in Fig. 2 and the peak diagrams from the carbon/oxygen spectra of the samples are shown in Fig. 3 and 4.

\subsection{Wettability experiments}

Studies show that the wettability of coal dust is closely related to its structure, surface properties, mineral composition and content. The wettability of coal dust is the theoretical foundation of the removal of dust using wet methods. Currently, the wettability of coal dust is mainly evaluated by measuring the contact angles of liquids on the coal dust surface and the speed that liquid penetrates the coal dust. A DSA100 optical dropshape analysis system is selected to measure the contact angles between the coal dust and distilled water. In addition, a downward penetration method is applied to measure the height that distilled water penetrates into the coal dust in 24 hours. The results are shown in Table 3.

Table 3 suggests that the wettability of coal dust continuously reduces with the increase in metamorphic degree. This variation in wettability has a certain relationship with the molecular structure of the coal dust itself. From the microscopic aspect of the functional groups, while the organic oxygen existing in the form of oxygen-containing functional groups enhances the hydrophilicity of coal dust, the relatively high carbon content contributes to the hydrophobicity of coal dust. A competition between these two factors governs the wettability of coal dust.

\section{Experimental results and analysis}

\subsection{Analysis of the carbon structure of coal dust}

Based on the peak fitting of the ${ }^{13} \mathrm{C} \mathrm{CP} / \mathrm{MAS}$ NMR spectra of the above samples (Fig. 1), the carbon structural parameters of six kinds of coal dust are listed in Table 4.

An NMR spectrum of coal primarily consists of two parts: aliphatic carbon (0-90 ppm) and aryl carbon (90-165 ppm). Judging from Fig. 1 and Table 4, it is clear that the NMR spectra vary with carbon rank. When the metamorphic degree increases, the fraction of aryl carbon increases. This indicates that the content of protonated carbon increases and the carbon content in the aromatic rings decreases. On the other hand, the fraction of aliphatic carbon in the coal structure continuously reduces, but each aliphatic carbon structure has certain distributions, all of which decrease with the increase in metamorphic degree. Overall, every structural parameter satisfies the rule of the recarburization and deoxygenation trend for the coal metamorphic effect.

\subsection{The distribution of carbon in coal dust}

To more directly observe the trend of how the carbon groups in coal dust change with the metamorphic degree, the peak areas of different types of carbon group in Fig. 1 are taken into consideration to calculate the percentage of each carbon-

Table 2 Industrial analysis and elemental analysis of coal dust

\begin{tabular}{|c|c|c|c|c|c|c|c|c|c|}
\hline \multirow[b]{2}{*}{ Coal type } & \multicolumn{4}{|c|}{ Industrial analysis/\% } & \multicolumn{5}{|c|}{ Elemental analysis/\% } \\
\hline & $\mathbf{M}_{\mathrm{ad}}$ & $A_{d}$ & $\mathrm{~V}_{\mathrm{daf}}$ & $\mathrm{FC}_{\mathrm{ad}}$ & $\mathrm{C}_{\mathrm{daf}}$ & $\mathrm{O}_{\mathrm{daf}}$ & $\mathrm{H}_{\mathrm{daf}}$ & $\mathrm{N}_{\mathrm{daf}}$ & $S_{\text {daf }}$ \\
\hline Long flame coal & 10.47 & 6.77 & 55.42 & 37.21 & 80.21 & 12.85 & 4.27 & 0.86 & 1.81 \\
\hline Gas coal & 5.49 & 7.35 & 40.11 & 52.44 & 83.89 & 10.09 & 4.96 & 0.82 & 0.24 \\
\hline Fat coal & 1.86 & 7.73 & 36.22 & 57.75 & 86.14 & 6.16 & 5.32 & 1.79 & 0.59 \\
\hline
\end{tabular}




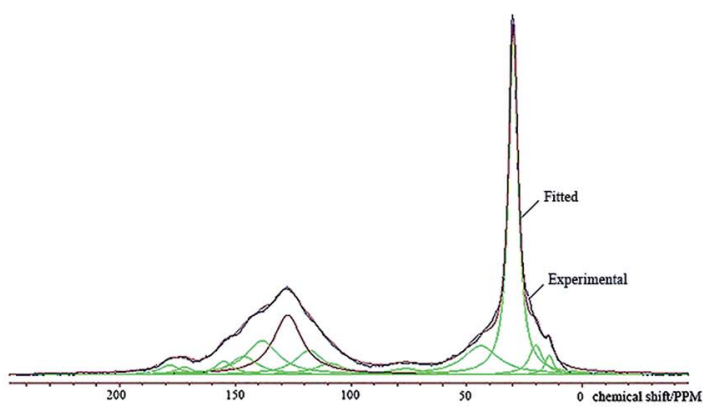

(a)

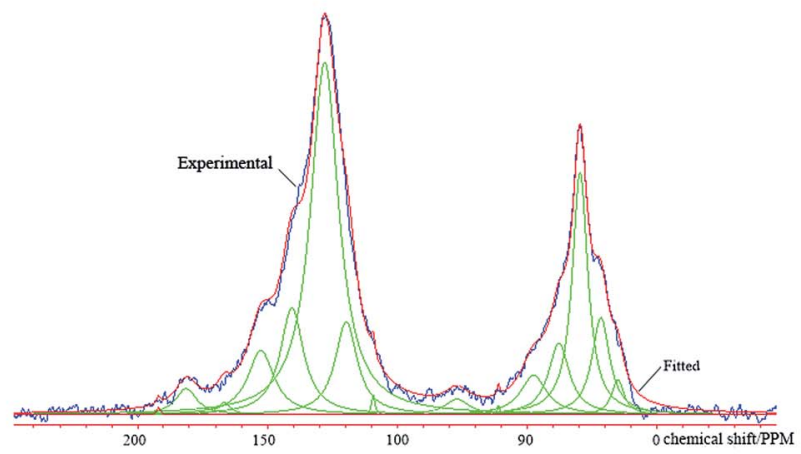

(c)

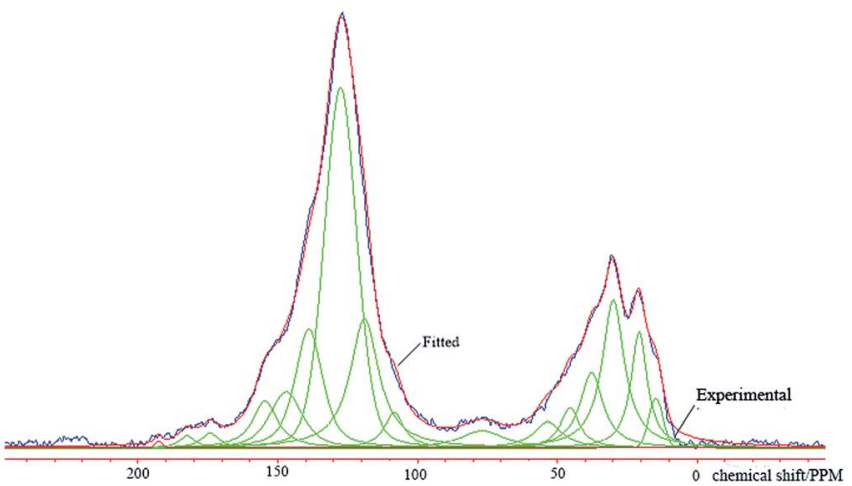

(e)

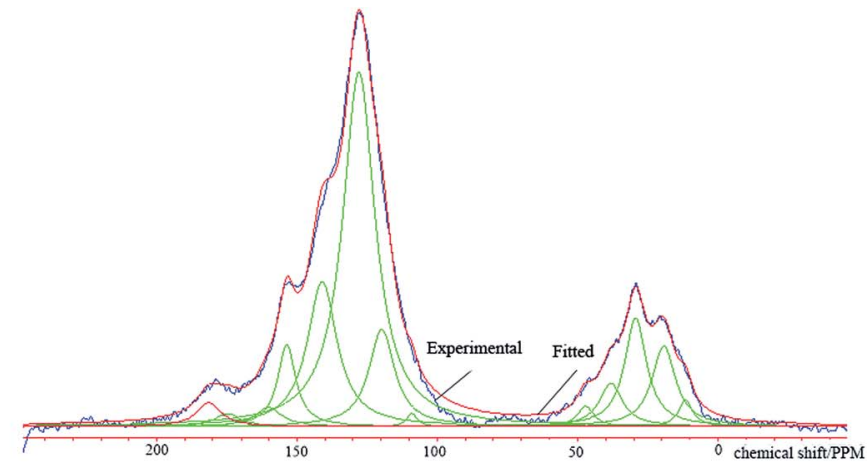

(b)

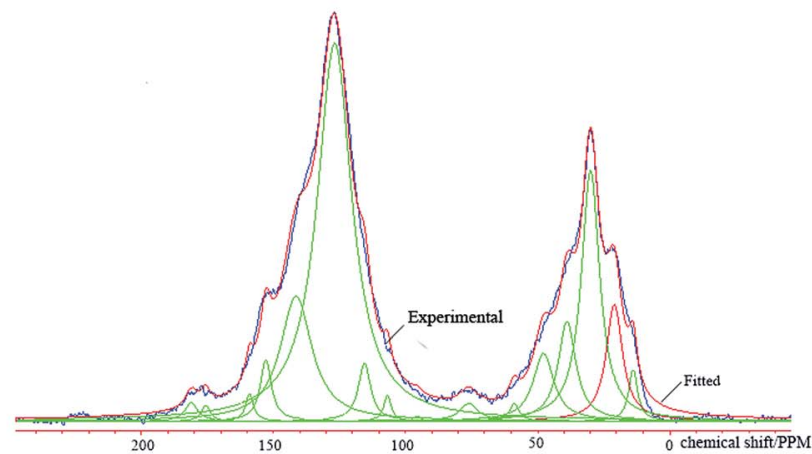

(d)

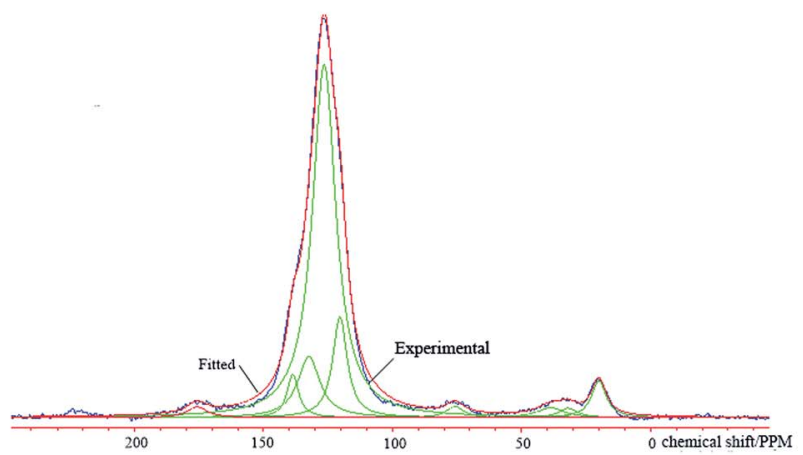

(f)

Fig. 1 Schemes of the ${ }^{13} \mathrm{C}$-NMR peaks for coal dust with different metamorphic degrees.

containing functional group in these six types of coal dust and the results are shown in Table 5 .

From the analysis, it is found that aromatic groups (Ar-C, H) are the major carbon-containing functional group. In a total of 100 carbon atoms, the number of aromatic carbons (or aromatic hydrocarbons) is the highest. In lignite, there are 38.9 carbon atoms directly bonded to hydrogen atoms. This number continues to increase with the increase in metamorphic degree. For instance, in anthracite, the value is 91. Combined with the NMR structural parameters, the aromatic hydrocarbons not only increase the number of carbons with the increasing metamorphic degree. The aromatic rings will connect with each other to form aromatic condensed rings that are more extendable, which was reported in previous work. ${ }^{24,25}$

The rest of the carbon functional groups are divided into two categories: most of them exist in the form of aliphatic side chains, comprising methyl $\left(\mathrm{CH}_{3}\right)$ and methylidyne $\left(\mathrm{CH}_{2}\right)$; few exist in the form of oxygen-containing functional groups, including carboxyl $(-\mathrm{COOH})$ and carbonyl $(\mathrm{C}=\mathrm{O})$ groups, ethers bonded to aromatic groups (Ar-O) and ethers bonded to aliphatic groups (R-O). ${ }^{26-29}$ The content of these two types of carbon group is related to each other to some extent in coal dust with different coal ranks: when the content of methyl $\left(\mathrm{CH}_{3}\right)$ and methylene $\left(\mathrm{CH}_{2}\right)$ is high, the content of aromatic and aliphatic ether bonds is also relatively 


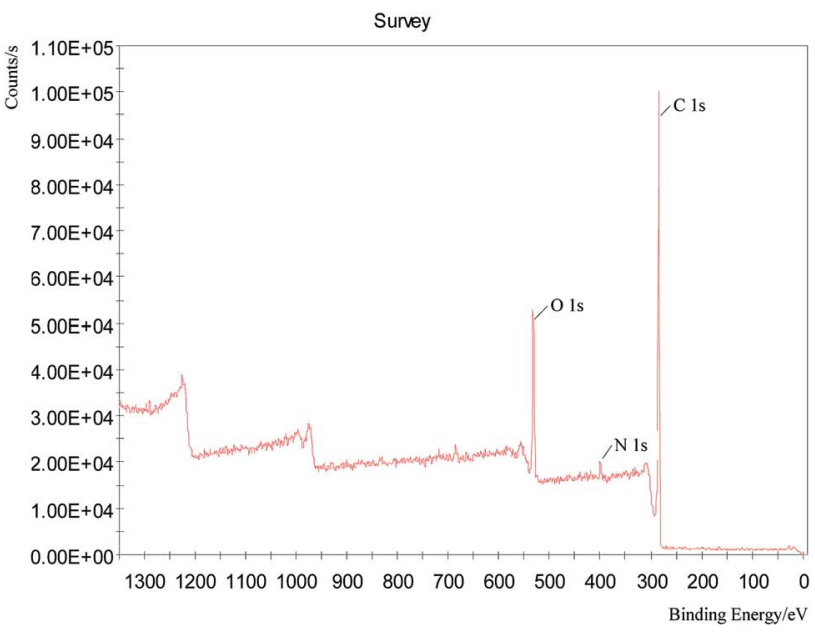

(a) Lignite

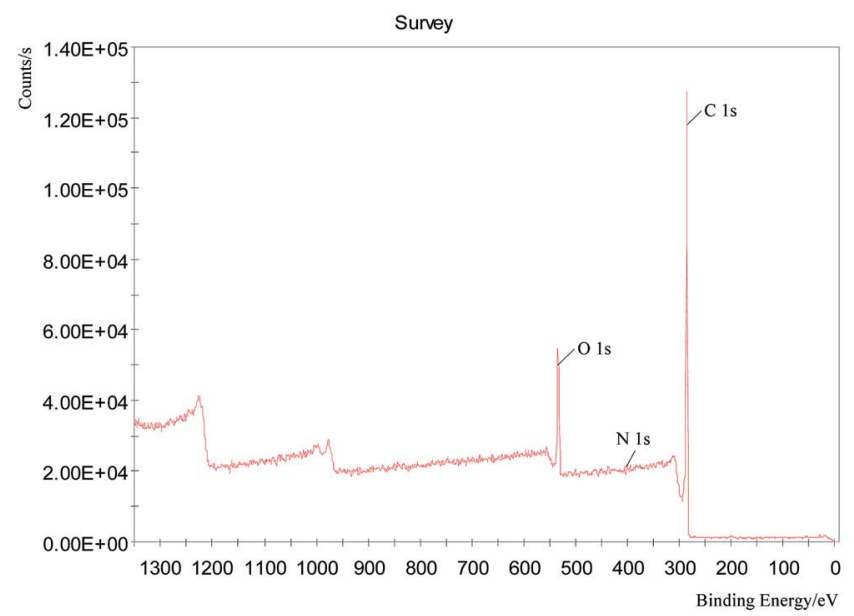

(c) Gas coal

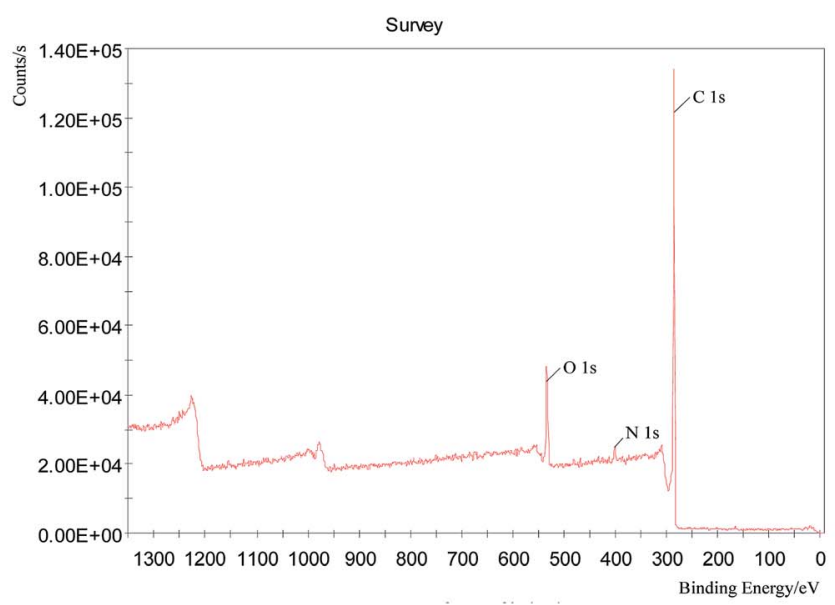

(e) Coking coal

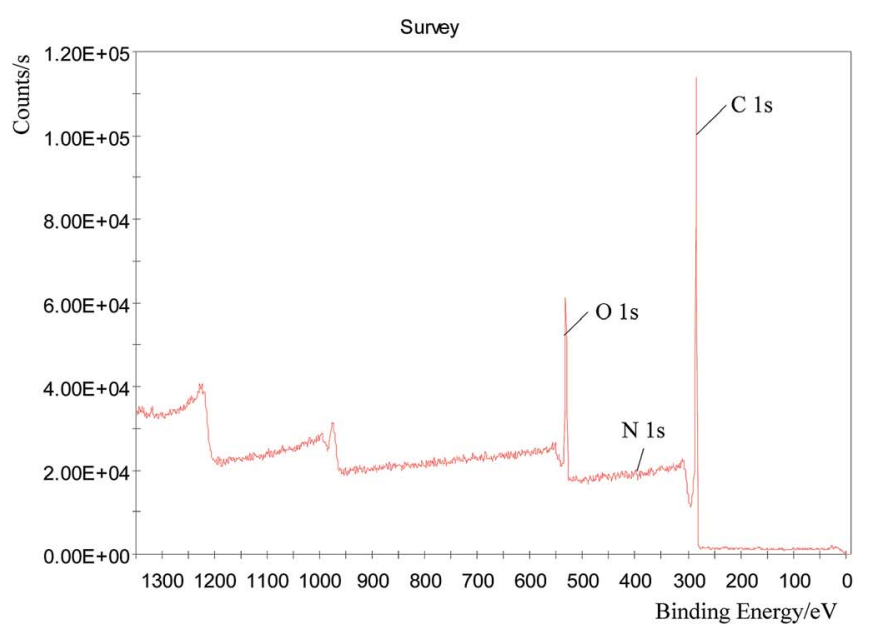

(b) Long fire coal

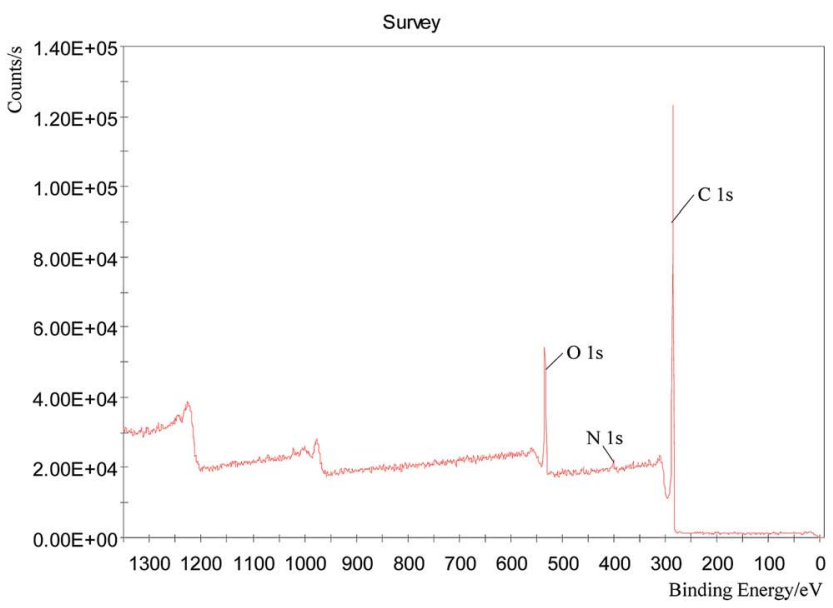

(d) Fat coal

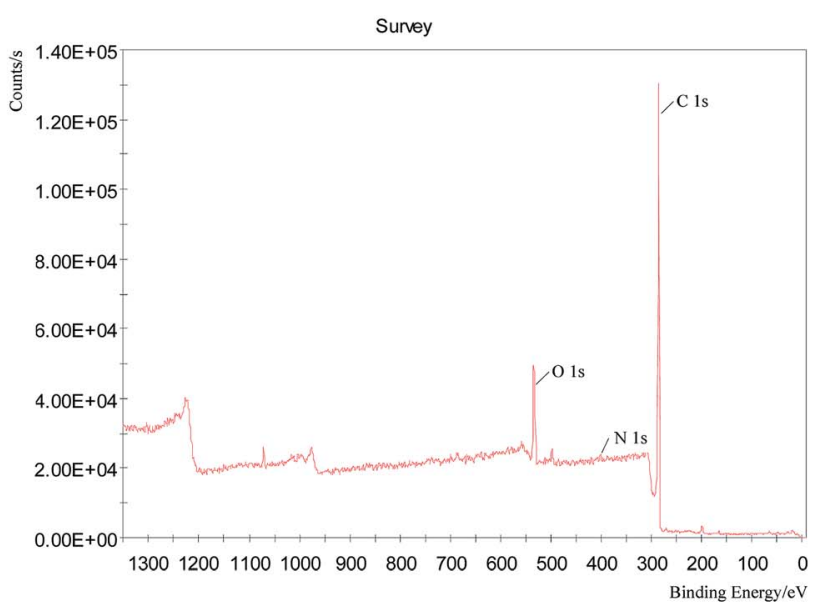

(f) Anthracite

Fig. 2 XPS spectra of the samples.

high, and the number of carboxyl $(-\mathrm{COOH})$ groups in the side chains is also high. These high amounts are primarily due to the fact that methyl, methylene, and carboxyl $(-\mathrm{COOH})$ groups are mainly bonded to aromatic rings as terminal groups. However, the change in carbonyl $(\mathrm{C}=\mathrm{O})$ content with the increasing metamorphic degree is not apparent. 


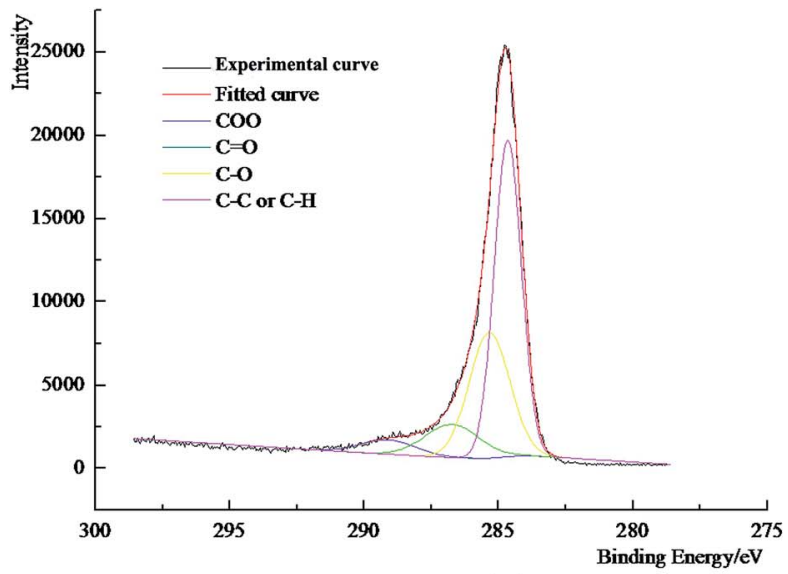

(a)

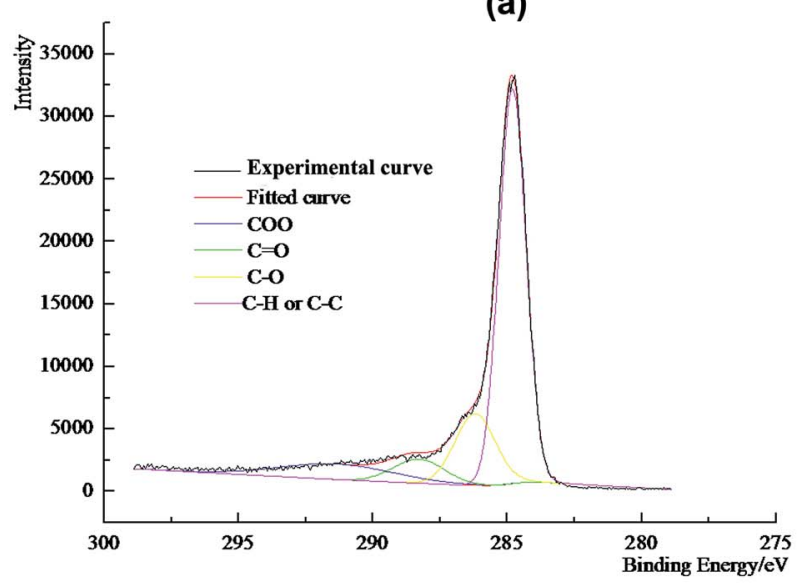

(c)

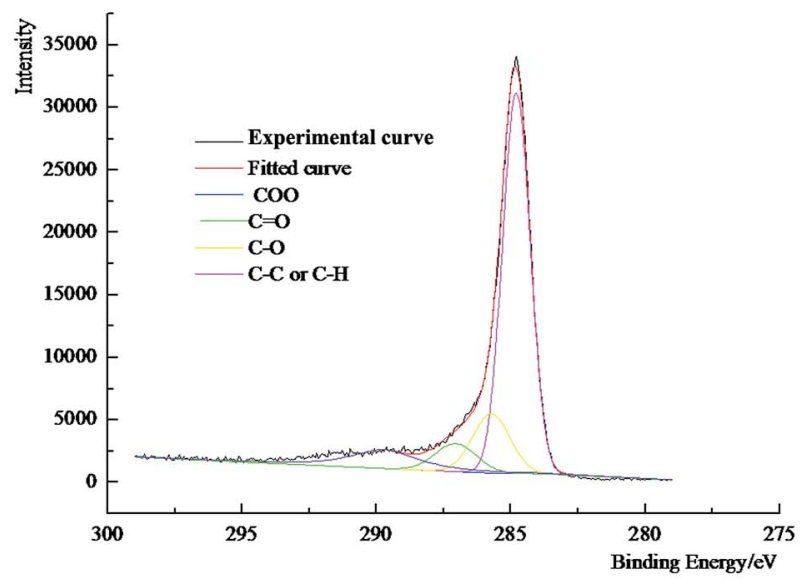

(e)

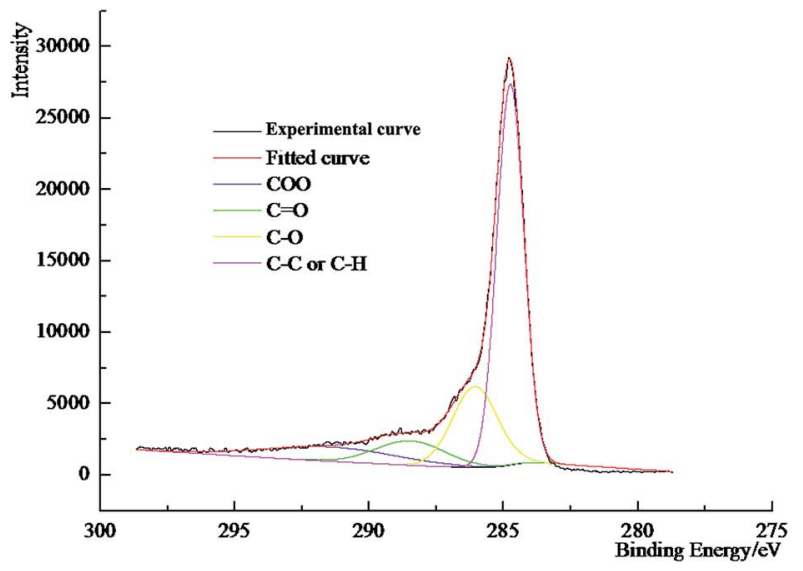

(b)

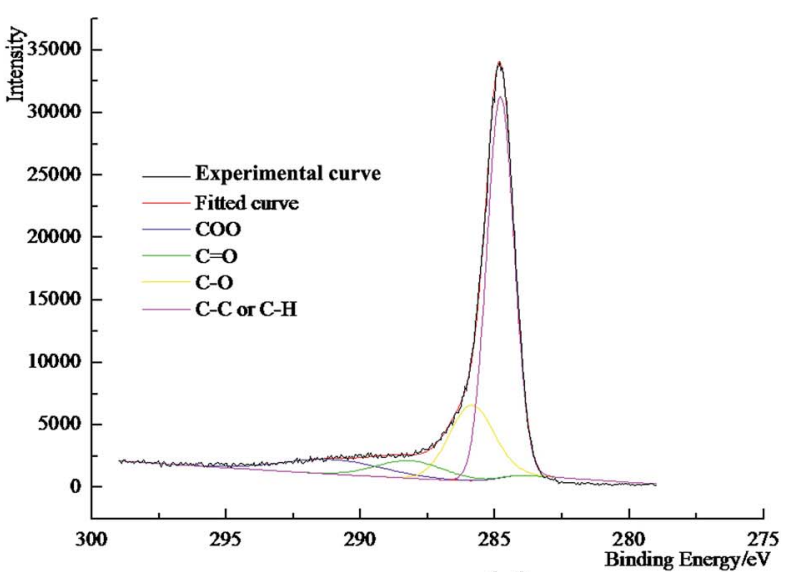

(d)

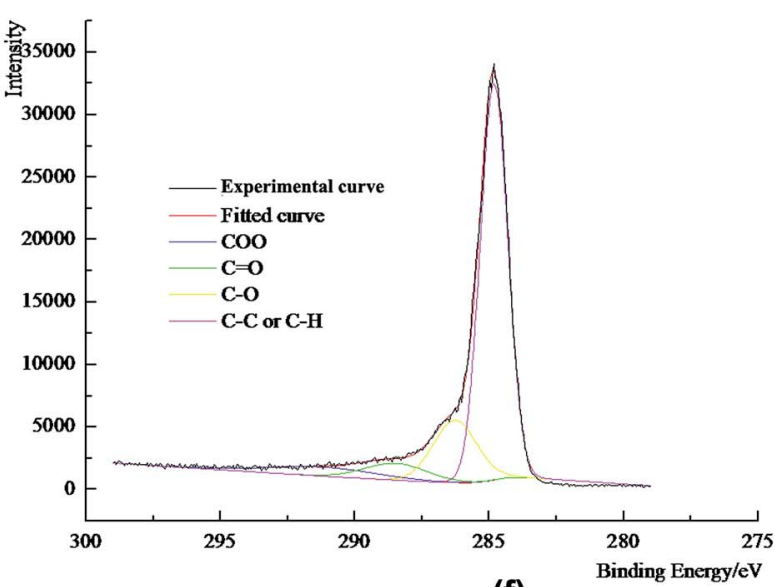

(f)

Fig. 3 XPS peak diagrams from the carbon spectra of the samples.

The above analysis shows that the surface groups of coal dust correlate with each other as the metamorphic degree varies. With the increase or decrease in content of a group due to a change in the metamorphic degree, there is normally an accompanying change in the number of other groups. Furthermore, there is a certain similarity between the evolution of groups with metamorphic degree, and thus their evolution cannot be described as simply an increase or decrease in the content of the group. To discuss the variance of distance for all kinds of carbon group, the SPSS distance analysis method is adopted to evaluate the relationships between these groups using a similarity measure between related parameters, which yields an approximate matrix.

Table 6 shows the similarity matrices regarding the distance analysis of variables for eight functional groups, namely, the Pearson correlation coefficient matrices, whose large values 


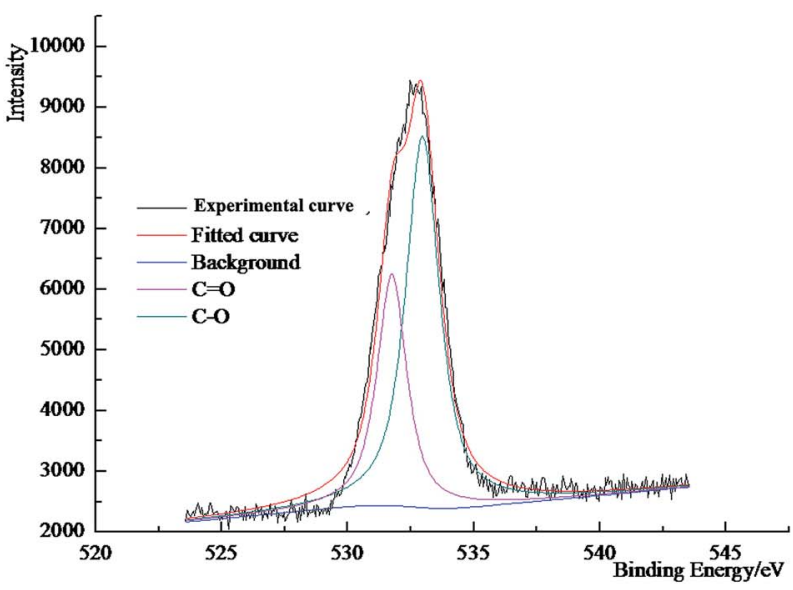

(a)

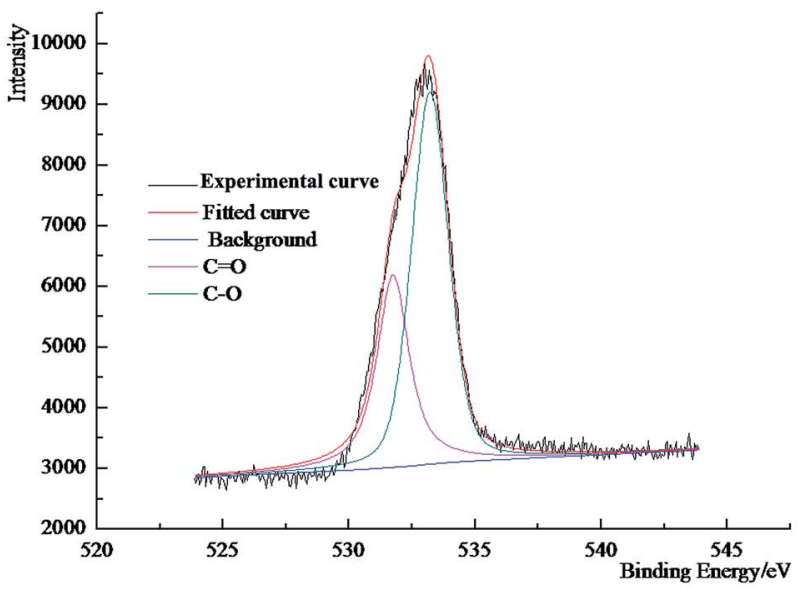

(c)

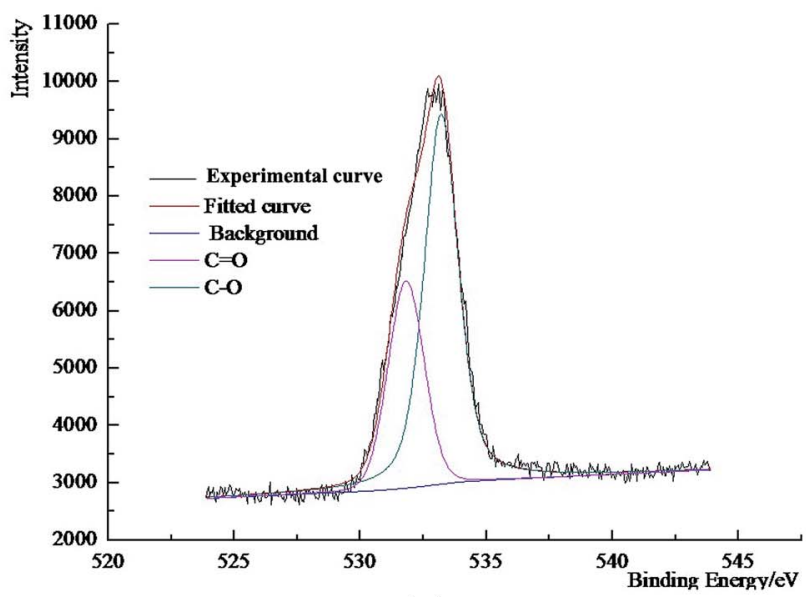

(e)

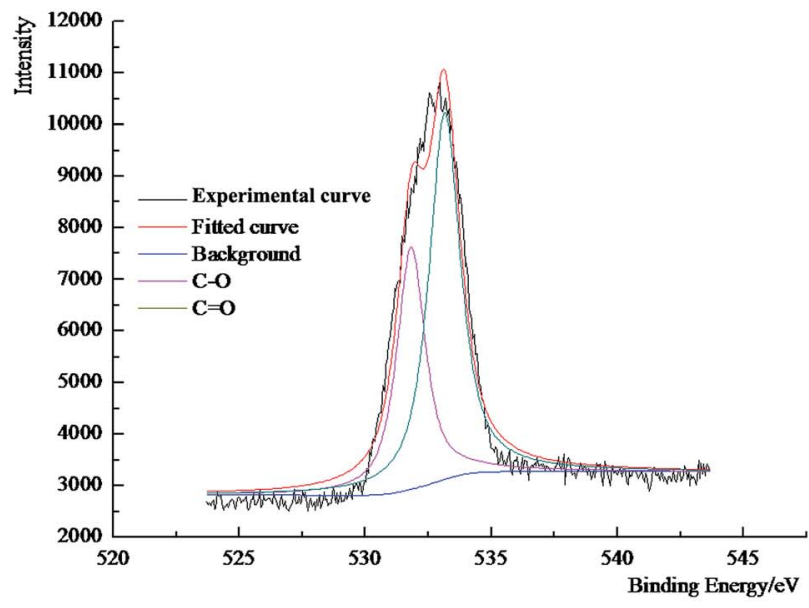

(b)

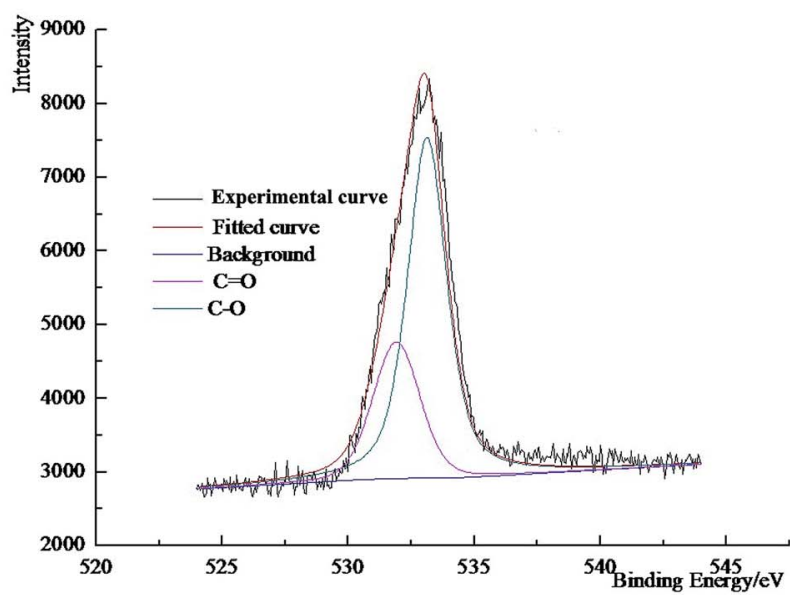

(d)

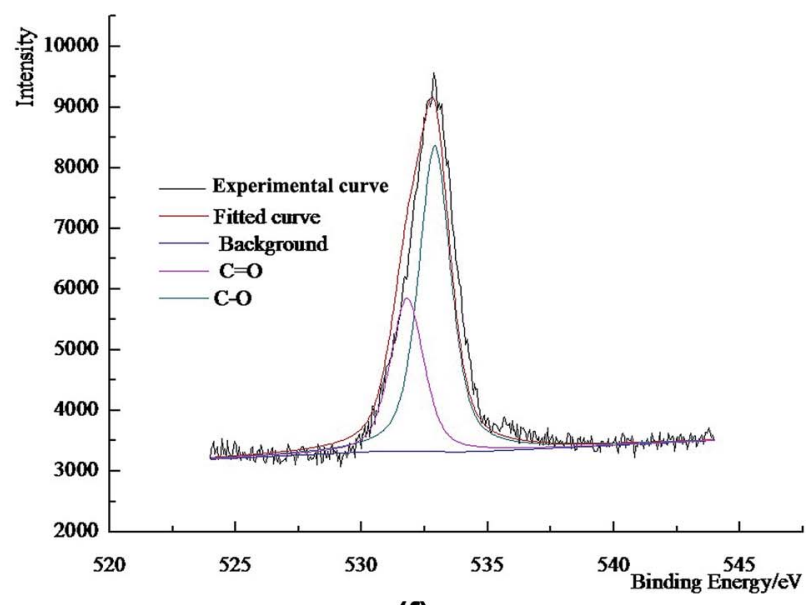

(f)

Fig. 4 XPS peak diagrams from the oxygen spectra of the samples.

indicate a large correlation between these groups as well as more similar variance trends with the increasing metamorphic degree. The correlation coefficients of most variables are larger than 0.5 , indicating a strong correlation. In Table 6, several couples of variables showing correlation coefficients larger than
0.95 are outlined using transverse lines, including carboxyl carbon $(-\mathrm{COOH})$ vs. aromatic hydrocarbon (Ar-C, $\mathrm{H})$ or methylene carbon $\left(\mathrm{CH}_{2}\right)$, aromatic ether carbon (Ar-O) vs. aromatic carbon (Ar-C, H), aromatic carbon (Ar-C, H) vs. methylene $\left(\mathrm{CH}_{2}\right)$ or ether carbon (R-O), and methylene $\left(\mathrm{CH}_{2}\right)$ vs. ether carbon $(\mathrm{R}-$ 
Table 3 The results of the wettability measurement of six kinds of coal dust

\begin{tabular}{|c|c|c|c|c|c|c|c|c|}
\hline \multirow[b]{2}{*}{ Coal type } & \multicolumn{4}{|c|}{ Contact angle $/^{\circ}$} & \multicolumn{4}{|c|}{ Wetting height/mm } \\
\hline & 1 & 2 & 3 & Average & 1 & 2 & 3 & Average \\
\hline Lignite & 46.70 & 48.12 & 46.34 & 47.05 & 14.6 & 14.4 & 13.9 & 14.3 \\
\hline Long flame coal & 55.19 & 56.43 & 56.22 & 55.95 & 13.1 & 12.7 & 12.8 & 12.9 \\
\hline Gas coal & 56.58 & 58.75 & 56.12 & 57.15 & 9.8 & 9.4 & 10.0 & 9.7 \\
\hline Fat coal & 62.07 & 62.67 & 62.38 & 62.37 & 6.3 & 6.6 & 6.8 & 6.6 \\
\hline Coking coal & 65.48 & 64.17 & 66.74 & 65.46 & 5.5 & 5.4 & 5.9 & 5.6 \\
\hline Anthracite & 72.34 & 74.12 & 72.19 & 72.88 & 3.9 & 4.4 & 4.6 & 4.3 \\
\hline
\end{tabular}

Table 4 The carbon structure of six kinds of coal dust ${ }^{a}$

\begin{tabular}{lllllllllllll}
\hline Coal type & $f_{\mathrm{a}}$ & $f_{\mathrm{a}}^{\mathrm{C}}$ & $f_{\mathrm{a}}$ & $f_{\mathrm{a}}^{\mathrm{N}}$ & $f_{\mathrm{a}}^{\mathrm{H}}$ & $f_{\mathrm{a}}^{\mathrm{P}}$ & $f_{\mathrm{a}}^{\mathrm{S}}$ & $f_{\mathrm{a}}^{\mathrm{B}}$ & $f_{\mathrm{al}}$ & $f_{\mathrm{al}}^{*}$ & $f_{\mathrm{al}}^{\mathrm{H}}$ & $f_{\mathrm{al}}^{\mathrm{O}}$ \\
\hline Lignite & 0.539 & 0.043 & 0.496 & 0.271 & 0.225 & 0.107 & 0.077 & 0.087 & 0.461 & 0.074 & 0.324 & 0.063 \\
Long flame coal & 0.636 & 0.031 & 0.605 & 0.295 & 0.310 & 0.094 & 0.092 & 0.109 & 0.364 & 0.141 & 0.178 & 0.045 \\
Gas coal & 0.714 & 0.019 & 0.695 & 0.322 & 0.373 & 0.090 & 0.092 & 0.140 & 0.286 & 0.076 & 0.166 & 0.044 \\
Fat coal & 0.747 & 0.028 & 0.719 & 0.272 & 0.447 & 0.035 & 0.084 & 0.153 & 0.254 & 0.072 & 0.145 & 0.037 \\
Coking coal & 0.818 & 0.012 & 0.806 & 0.276 & 0.530 & 0.034 & 0.061 & 0.181 & 0.182 & 0.055 & 0.095 & 0.032 \\
Anthracite & 0.927 & 0.011 & 0.916 & 0.279 & 0.637 & 0.006 & 0.051 & 0.222 & 0.073 & 0.035 & 0.028 & 0.010
\end{tabular}

${ }^{a}$ Note: the following abbreviations are used: $f_{\mathrm{a}}$ - aromatic carbon; $f_{\mathrm{a}}^{\mathrm{C}}$ - carbonyl carbon with a chemical shift $>165$ ppm; $f_{\mathrm{a}}$-aromatic ring carbon; $f_{\mathrm{a}}^{\mathrm{N}}-$ non-protonated carbon; $f_{\mathrm{a}}^{\mathrm{H}}$ - protonated carbon; $f_{\mathrm{a}}^{\mathrm{P}}-$ phenolic or phenolic ether-based carbon; $f_{\mathrm{a}}^{S}-$ alkylated aromatic carbon; $f_{\mathrm{a}}^{\mathrm{B}}-$ aromatic bridgehead carbon; $f_{\mathrm{al}}$ - aliphatic carbon; $f_{\mathrm{al}}^{*}$ - aliphatic methyl or aryl methyl; $f_{\mathrm{al}}^{\mathrm{H}}$ - quaternary carbon or methylene carbon; and $f_{\mathrm{al}}^{\mathrm{O}}-$ oxygenbonded aliphatic carbon. Among them $f_{\mathrm{a}}+f_{\mathrm{al}}=1$.

Table 5 Distribution of the carbon-containing functional groups

\begin{tabular}{lllrlrrr}
\hline Coal type & $\mathrm{C}=\mathrm{O}$ & $-\mathrm{COOH}$ & $\mathrm{Ar}-\mathrm{O}$ & $\mathrm{Ar}-\mathrm{C}, \mathrm{H}$ & $\mathrm{CH}_{3}$ & $\mathrm{CH}_{2}$ & $\mathrm{R}-\mathrm{O}$ \\
\hline Lignite & 1.2 & 3.1 & 10.7 & 38.9 & 7.4 & 32.4 & 6.3 \\
Long flame coal & 0.8 & 2.3 & 9.4 & 51.1 & 14.1 & 17.8 & 4.5 \\
Gas coal & 0.4 & 1.5 & 9.0 & 60.5 & 7.6 & 16.6 & 4.4 \\
Fat coal & 1.5 & 1.3 & 3.5 & 68.3 & 7.2 & 14.5 & 3.7 \\
Coking coal & 0.5 & 0.7 & 3.4 & 77.2 & 5.5 & 9.5 & 3.2 \\
Anthracite & 0.8 & 0.3 & 0.6 & 91.0 & 3.5 & 2.8 & 1.0
\end{tabular}

O). This means that with the increasing metamorphic degree, carboxyl carbon $(-\mathrm{COOH})$, aromatic hydrocarbon (Ar-C, H), methylene carbon $\left(\mathrm{CH}_{2}\right)$ and ether carbon $(\mathrm{Ar}-\mathrm{O}, \mathrm{R}-\mathrm{O})$ have close relationships and all likely belong to the same cluster. Combined with the data in Table 4, it is clear that the evolution of different carbon groups with the increasing metamorphic degree is a process of cluster increase/decrease. Since the content of aromatic carbon (Ar-C) is much higher than that of other types of carbon, it is separately monitored as an essential index to represent the evolution of the carbon functional groups in coal. In contrast, with the increasing metamorphic degree, the number of aromatic groups continuously increases and the content of carboxyl-carbon $(-\mathrm{COOH})$, methylene carbon $\left(\mathrm{CH}_{2}\right)$ and ether carbon (Ar-O, R-O) simultaneously decreases. The reduction rate of carboxyl carbon $(-\mathrm{COOH})$ is closest to the increase rate of aromatic hydrocarbon (Ar-C, H). The evolution of methyl carbon $\left(\mathrm{CH}_{3}\right)$ and carbonyl $(\mathrm{C}=\mathrm{O})$ carbon changes irregularly, which is different from the evolution laws of the other carbon groups.

\subsection{The distribution of oxygen in coal dust}

The types of oxygen-containing functional group on the surface of coal dust primarily consist of single bonded oxygen (ether

Table 6 Approximate matrix of the distance analysis on the carbon groups

\begin{tabular}{|c|c|c|c|c|c|c|c|c|}
\hline Groups & \multicolumn{8}{|c|}{ Correlation between variables } \\
\hline$-\mathrm{COOH}$ & 0.337 & 1.000 & 0.909 & -0.985 & 0.629 & 0.962 & 0.933 & 0.337 \\
\hline Ar-O & -0.038 & 0.909 & 1.000 & -0.950 & 0.678 & 0.869 & 0.912 & -0.038 \\
\hline Ar-C, H & -0.252 & -0.985 & -0.950 & 1.000 & -0.660 & -0.961 & -0.971 & -0.252 \\
\hline $\mathrm{R}-\mathrm{O}$ & 0.233 & 0.933 & 0.912 & -0.971 & 0.540 & 0.967 & 1.000 & 0.233 \\
\hline $\mathrm{C}=\mathrm{O}$ & 1.000 & 0.337 & -0.038 & -0.252 & 0.039 & 0.357 & 0.233 & 1.000 \\
\hline
\end{tabular}


bond and hydroxyl), carbonyl groups and carboxyl groups. The relative population of carbonyl and carboxyl groups can be obtained from the XPS spectra to obtain the content of organic carbon in each of these two functional groups. However, limited by resolution, XPS cannot distinguish between the $\mathrm{C}-\mathrm{O}$ of an ether bond (-O-) and of the hydroxyl group $(-\mathrm{OH})$. Therefore, in order to obtain the relative percentages of ether $(-\mathrm{O}-)$ and hydroxyl $(-\mathrm{OH})$ on the surface of the coal dust, comprehensive analysis of the carbon spectra and the oxygen spectra is required and the analytical results are shown in Table 7.

From Table 7, it is clear that the oxygen-containing functional groups have huge differences when distributed on the surfaces of coals with different coal ranks, and there is a large amount of carboxyl (-COOH) and hydroxyl $(-\mathrm{OH})$ on low ranked coals (lignite, long flame coal and gas coal). These two groups together cover up to $65.97 \%, 61.29 \%$ and $51.70 \%$, respectively, of the oxygen-containing functional groups, exceeding half of the total amount of oxygen-containing functional groups. In lignite, long flame coal and gas coal, the content of carbonyl in the oxygen-containing functional groups is as low as $11.52 \%$, $8.24 \%$ and $15.31 \%$, respectively. With the increase in metamorphic degree, the amounts of carboxyl $(-\mathrm{COOH})$ and hydroxyl $(-\mathrm{OH})$ both decrease. However, the magnitude of the decrease is not large. For different low-ranked coals, the XPS results indicate that there are rich and highly active carboxyl $(-\mathrm{COOH})$ and hydroxyl $(-\mathrm{OH})$ groups and the percentage of carbonyl groups is the smallest, which is in accordance with the result from the classical chemical analysis. ${ }^{30}$

In medium-high metamorphic coals (fat coal, coking coal and anthracite), the ether (-O-) and carbonyl content increases gradually. Together they account for $62.31 \%, 73.93 \%$ and $80.79 \%$, respectively, of the oxygen-containing functional groups, while the corresponding content of carboxyl $(-\mathrm{COOH})$ and hydroxyl $(-\mathrm{OH})$ reduces to values below $20 \%$. In particular, the coverage of carboxyl $(-\mathrm{COOH})$ on coal surfaces with

Table 7 The distribution of the oxygen-containing functional groups on the dust surface

\begin{tabular}{llrrr}
\hline & \multicolumn{4}{l}{ Mole percentage/\% } \\
\cline { 2 - 5 } Coal type & $\mathrm{C}-\mathrm{OH}$ & $\mathrm{COOH}$ & $\mathrm{C}=\mathrm{O}$ & $\mathrm{C}-\mathrm{O}-\mathrm{C}$ \\
\hline Lignite & 38.40 & 27.57 & 11.52 & 22.51 \\
Long flame coal & 30.00 & 31.29 & 8.24 & 30.48 \\
Gas coal & 28.92 & 22.78 & 15.31 & 32.98 \\
Fat coal & 22.79 & 14.89 & 12.37 & 49.94 \\
Coking coal & 18.05 & 8.02 & 25.14 & 48.79 \\
Anthracite & 13.02 & 6.19 & 29.38 & 51.41
\end{tabular}

a medium-high metamorphic degree is less than $15 \%$, and is merely $6.19 \%$ in anthracite coal. In contrast, the low reactivity ether content reaches $51.41 \%$, showing that it dominates. For medium-high ranked coals, the XPS results show that there is a large amount of low reactivity ether $(-\mathrm{O}-)$ and carbonyl $(\mathrm{C}=\mathrm{O})$ groups and the percentage of carboxyl $(-\mathrm{COOH})$ groups is the smallest.

\subsection{Analysis of the relationship between the carbon composition and the wettability of coal}

Generally, the wettability of coal depends on the coal rank. With the increase in coal rank, the number of hydrophobic organic components increases, whereas the number of hydrophilic oxygen-containing functional groups decreases, leading to a reduction in the wettability. By using SPSS software, the correlation between the microscopic molecular structure and wettability is analyzed in Table 8. Six structures of $f_{\text {a }}$, $f_{\mathrm{a}}^{\mathrm{H}}, f_{\mathrm{a}}^{\mathrm{B}}, f_{\mathrm{a}}^{\mathrm{P}}, f_{\mathrm{al}}^{\mathrm{H}}$ and $f_{\mathrm{al}}^{\mathrm{O}}$ are significantly correlated (all correlation coefficients are higher than 0.9) in the test of significance level (two-sided). Among them, $f_{\mathrm{a}}, f_{\mathrm{a}}^{\mathrm{H}}$ and $f_{\mathrm{a}}^{\mathrm{B}}$ are positively correlated, whereas $f_{\mathrm{a}}^{\mathrm{P}}, f_{\mathrm{al}}^{\mathrm{H}}$ and $f_{\mathrm{al}}^{\mathrm{O}}$ are negatively correlated. As a consequence, these six parameters can be considered as wettability correlation factors.

The specific relationships between the wettability and the above six carbon structures are shown as follows: (1) $f_{\text {a }}^{\prime}$ continuously increases, $f_{\mathrm{al}}^{\mathrm{H}}$ continuously decreases, long aliphatic carbon chains break and condense to form aromatic rings, the aromatization degree of the coal becomes higher and the hydrophobicity increases; (2) $f_{\mathrm{a}}^{\mathrm{H}}$ continuously increases, making aryl carbons more and more concentrated in protonated carbons and the functional groups on the aromatic rings reduce, which is disadvantageous to the hydrophilicity; (3) the increase of the $f_{\mathrm{a}}^{\mathrm{B}}$ content also demonstrates the change of the aromatic structure, namely, aromatic rings join to form condensed aromatic fused rings, reducing the adsorption of water; (4) $f_{\mathrm{a}}^{\mathrm{p}}$ and $f_{\mathrm{al}}^{\mathrm{O}}$ largely decrease and the content of oxygenrelated functional groups continuously reduces, thus reducing the hydrophilicity. J. Wang et al. ${ }^{31}$ studied the influence of the coal structure on its pyrolysis. They found that the pyrolysis process mainly involves the decomposition of hydrogencontaining groups and a decrease in the number of oxygengroups at high temperatures. Therefore, the decrease in the number of these groups will directly affect the chemical properties of coals.

The wettability characteristics and NMR tests prove that with the increase in metamorphic degree, the factors influencing the wettability vary and the wettability of coal reduces. To explore the interaction mechanism between the change of influencing

Table 8 Correlation analysis of carbon structural parameters and the macroscopic wettability ${ }^{a}$

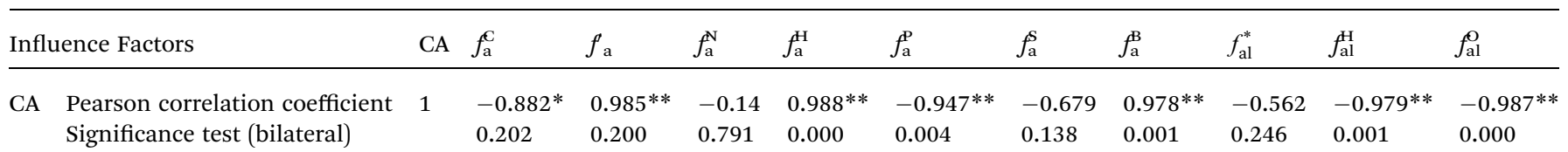

${ }^{a}$ Note: CA - contact angle; *significantly correlated at 0.05 level (two-sided); **significantly correlated at 0.01 level (two-sided). 
Table 9 Changing rates of wettability influencing factors ${ }^{a}$

Change parameter

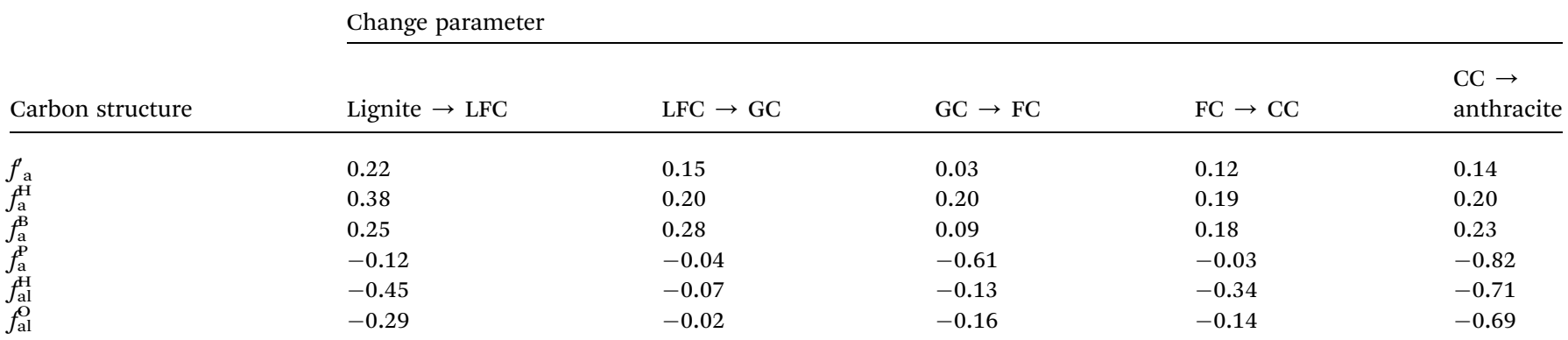

${ }^{a}$ Note: LFC - long flame coal; GC - gas coal; FC - fat coal; and CC - coking coal.

factors and wettability, the gradients of six characteristic structural parameters with coal ranks are compared, as shown in Table 9.

From Table 9, it can be seen that the gradient of each parameter is most significant when lignite evolves into low-rank bituminous coal and when bitumite evolves into anthracite, because the peak values of the parameter gradients all appear in these two stages. This conclusion was also drawn by Y. Qin et $a l^{32}$ Therefore, lignite and anthracite have relatively large differences in wettability compared to other types of coal. ${ }^{33}$ During the evolution stage of bituminous coal with a low metamorphic degree (long flame coal $\rightarrow$ gas coal), the gradients of the related parameters of aryl carbon structures $\left(f_{\mathrm{a}}^{\mathrm{a}}, f_{\mathrm{a}}^{\mathrm{H}}, f_{\mathrm{a}}^{\mathrm{B}}\right.$ and $f_{\mathrm{a}}^{\mathrm{a}}$ ) are significantly higher than those of aliphatic carbon structures $\left(f_{\mathrm{al}}^{\mathrm{H}}\right.$ and $\left.f_{\mathrm{al}}^{\mathrm{O}}\right)$, indicating that aromatization plays a dominating role in this stage. With the increase in the coal dust metamorphic degree, until the evolution stage of bitumite with a medium metamorphic degree (gas coal $\rightarrow$ fat coal), the amplitude of variation concerning aliphatic carbon structures significantly increases, and at this time, $f_{\text {a }}^{\text {g greatly decreases, }}$ indicating that the aryl side chains continue to decrease and the oxygen-containing functional groups also reduce significantly. During the stage from fat coal $\rightarrow$ coking coal, each parameter still increases or decreases at a certain rate of change, aromatic rings are further condensed to form macromolecular polynuclear aromatic hydrocarbons and oxygen-containing functional groups continue to fall off.

From the above evolution law of these parameters, the microscopic mechanism causing coals of various ranks to have different wettabilities could be proposed. Low rank coals have a high percentage of polar groups, which make the structures simple, thus they have the best wettability. During metamorphic evolution, aliphatic carbon condenses to form aromatic rings and thus the aromatic carbon abundance increases whereas the oxygen-containing groups are almost intact. In this case, the reduction of wettability should be caused by aromatic carbon. The aromatic rings then continue to condense by dropping most of their oxygen-containing groups, thus leading to a poor wettability. In the highest metamorphic stage, all the oxygen-containing groups fall off and the aromatic rings present the highest condensation degree and lowest activity, which results in the worst wettability.

\subsection{The influence of carbon- and oxygen-containing group evolution on the wettability of coal dust}

3.5.1 The effect of surface carbon- and oxygen-containing groups on wettability. Based on the contact angle tests, the effect of surface carbon- and oxygen-containing groups on wettability is shown in Fig. 5 .

Judging from the carbon curves in Fig. 5, the wettability of coal dust is sensitive to the content of aromatic carbon (Ar-C, $\mathrm{H})$, methylene $\left(\mathrm{CH}_{2}\right)$ and ether carbon (Ar-O, R-O). Generally, with the upgrading of coal rank, the population of aromatic carbon increases, that of methylene decreases and the wettability also reduces. Other carbon-containing groups have no significant variation trend with changes of coal rank.

On the other hand, the oxygen curves in Fig. 5 indicate that the wettability of coals is greatly influenced by the polar oxygencontaining groups (carboxyl and hydroxyl). As the coal rank increases, the polar oxygen groups gradually disappear, leading to an increase in contact angle which indicates a decrease in wettability. At the same time, there is no obvious variation trend of carbonyl and ether-based oxygen with less of a change in contact angle. Therefore it is not possible to deduce the relationship between these two variables.

3.5.2 Quantitative analysis of the effect of surface carbonand oxygen-containing groups on wettability. Taking into consideration the wetting measurement of coals, the correlation between each functional group and the wettability (contact angle) of coal is preliminarily determined by a simple linear regression analysis between the carbon/oxygen-containing groups and the wettability (contact angle) in Tables 10 and 11. By analyzing the influence of the evolution of carbon and oxygen groups on the wettability of coal dust, the carbonyl $(\mathrm{C}=$ O) carbon is found not to correlate with the wettability. The methyl carbon $\left(\mathrm{CH}_{3}\right)$ and carbonyl $(\mathrm{C}=\mathrm{O})$ oxygen show a weak correlation with the wettability with correlation coefficients $\left(R^{2}\right)$ of 0.15 and 0.59 , respectively. The correlation coefficients $\left(R^{2}\right)$ between other groups and the wettability (contact angle) are all larger than 0.7 , indicating their relatively strong correlation. In particular, the most significant correlations exist between the wettability and the aromatic carbon $(\mathrm{Ar}-\mathrm{C}, \mathrm{H})$, methylene carbon $\left(\mathrm{CH}_{2}\right)$, ether carbon (Ar-O, R-O) and hydroxyl oxygen $(-\mathrm{OH})$, with correlation coefficients $\left(R^{2}\right)$ as high as $0.98,0.95,0.97$ and 0.98 , respectively. 

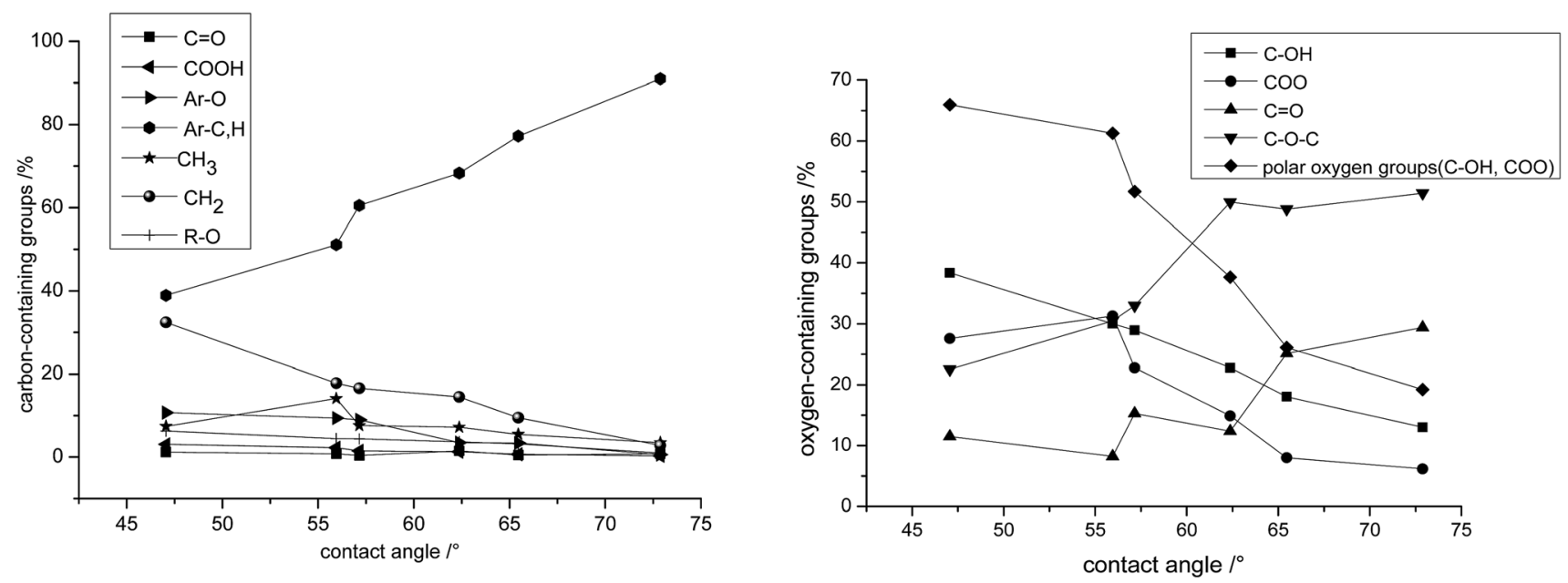

Fig. 5 The relationship between the wettability and surface content of carbon-containing and oxygen-containing groups of coal dust.

Table 10 Correlation between wettability and carbon groups

\begin{tabular}{lll}
\hline Group & Regression equation & $R^{2}$ \\
\hline $\mathrm{C}=\mathrm{O}$ & - & - \\
$-\mathrm{COOH}$ & $Y=72.92-8.33 x$ & 0.92 \\
$\mathrm{Ar}-\mathrm{O}$ & $Y=72.59-2.04 x$ & 0.87 \\
$\mathrm{Ar}-\mathrm{C}, \mathrm{H}$ & $Y=29.67+0.47 x$ & 0.98 \\
$\mathrm{CH}_{3}$ & $Y=70.69-1.4 x$ & 0.15 \\
$\mathrm{CH}_{2}$ & $Y=73.83-0.88 x$ & 0.95 \\
$\mathrm{R}-\mathrm{O}$ & $Y=79.41-5 x$ & 0.97
\end{tabular}

Table 11 Correlation between wettability and oxygen groups

\begin{tabular}{lll}
\hline Group & Regression equation & $R^{2}$ \\
\hline$-\mathrm{OH}$ & $Y=84.51-0.97 x$ & 0.98 \\
$\mathrm{COOH}$ & $Y=74.05-0.75 x$ & 0.72 \\
$\mathrm{C}=\mathrm{O}$ & $Y=45.4+0.87 x$ & 0.59 \\
$\mathrm{C}-\mathrm{O}-\mathrm{C}$ & $Y=33.68+0.67 x$ & 0.82
\end{tabular}

\section{Conclusions}

NMR experiments revealed that as the coal rank increases the number of aromatic carbons increases whereas the number of alkyl carbons decreases. Among them, aromatic carbon (Ar-C, $\mathrm{H})$, carboxyl carbon $(-\mathrm{COOH})$, methylene carbon $\left(\mathrm{CH}_{2}\right)$ and ether carbon (Ar-O, R-O) have similar variation trends. The latter three all decrease when the number of aromatic carbons (Ar-C, H) increases. The XPS spectra indicate that the number of carboxyl and hydroxyl groups gradually decreases when the coal rank increases. The less active ether $(-\mathrm{O}-)$ and carbonyl $(\mathrm{C}=\mathrm{O})$ groups dominate in the highly ranked coals. From the evolution of structural parameters, the number of hydrophobic organic components increases and the number of hydrophilic oxygencontaining groups decreases, leading to a rather poor wettability. Qualitatively, low ranked coals have a better wettability because of their abundant oxygen-containing groups and simple aromatic groups. As the ranking increases, the aromatic rings gradually condense and the oxygen-containing groups fall off, leading to a poor wettability. Quantitatively, unitary linear recursive analysis shows that aromatic carbon $(\mathrm{Ar}-\mathrm{C}, \mathrm{H})$ and hydroxyl oxygen $(-\mathrm{OH})$ have the strongest relationship with the wettability (contact angle), as indicated by a correlation coefficient as high as 0.98 . Unexpectedly, methylene $\left(\mathrm{CH}_{2}\right)$ and ether carbons (Ar-O, R-O), as major factors influencing the wettability of coal dusts, possess correlation coefficients of 0.95 and 0.97 towards the wettability, respectively.

\section{Conflicts of interest}

There are no conflicts to declare.

\section{Acknowledgements}

This work was supported financially by the National Natural Science Foundation of China (Grant no. 51474139 and 51774198), the Outstanding Youth Fund Project of Provincial Universities in Shandong Province (Grant no. ZR2017JL026, the SDUST Research Fund (Grant no. 2014JQJH106), the Key Research and Development Program of Shandong Province (Grant no. 2016GSF120002), the Taishan Scholar Talent Team Support Plan for Advantaged and Unique Discipline Areas, the Qingdao City Science and Technology Project (Grant no. 16-6-252-nsh), the China Postdoctoral Science Foundation Funded Special Project (Grant no. 2016T90642), the China Postdoctoral Science Foundation Funded Project (Grant no. 2015M570602) and the Qingdao Postdoctoral Applied Research Project (Grant no. 2015194).

\section{References}

1 D. Prostański, J. Sust. Min., 2015, 14, 108-114.

2 P. R. Amyotte, A. Basu and F. I. Khan, Process Saf. Environ. Prot., 2003, 81, 457-462.

3 A. S. Laney, D. N. Weissman and J. Occup, Environ. Med., 2014, 56(suppl. 10), S18-S22. 
4 C. K. Man and M. L. Harris, J. Loss Prev. Process Ind., 2014, 27, 49-54.

5 M. J. Sapko, K. L. Cashdollar and G. M. Green, J. Loss Prev. Process Ind., 2007, 20, 616-620.

6 W. M. Cheng, W. Nie, G. Zhou, Y. Yu, Y. Ma and J. Xue, Saf. Sci., 2012, 50, 851-856, in Chinese.

7 D. Prostański, J. Sust. Min., 2013, 12, 29-34.

8 D. W. Fuerstenau, J. Diao and M. C. Williams, Colloids Surf., 1991, 60, 127-144.

9 T. Young, Philos. Trans. R. Soc. London, 1805, 95, 65-87.

10 R. J. Crawford, D. W. Guy and D. E. Mainwaring, Fuel, 1994, 73, 742-746.

11 D. V. Keller, Colloids Surf., 1987, 22, 21-35.

12 J. A. Gutierrez-Rodriguez, R. J. Purcell and F. F. Aplan, Colloids Surf., 1984, 12, 1-25.

13 A. Sarkar, D. Kocaefe, Y. Kocaefe, D. Sarkar, D. Bhattacharyay and B. Morais, Fuel, 2014, 117, 598-607.

14 H. Guo and A. Kantzas, J. Can. Pet. Technol., 2009, 48, 40-46.

15 H. Chang, H. Zhang, Z. Jia, X. Li, W. Gao and W. Wei, Colloids Surf., A, 2016, 494, 59-64.

16 T. Chaturvedi, J. M. Schembre and A. R. Kovscek, Int. J. Coal Geol., 2009, 77, 34-42.

17 F. Gao and X. Shan, J. Fuel Chem. Technol., 2012, 40, 769-775. 18 D. P. Savitskyi, J. Water Chem. Tech., 2015, 37, 155-160.

19 K. N. Shojai, E. S. Rudolph, K. H. Wolf and S. N. Ashrafizadeh, J. Colloid Interface Sci., 2011, 364, 237.

20 X. Cao, M. A. Chappell, A. Schimmelmann, M. Mastalerz, Y. Li, W. Hu and J. Mao, Int. J. Coal Geol., 2013, 108, 53-64.
21 G. N. Okolo, H. W. J. P. Neomagus, R. C. Everson, M. J. Roberts, J. R. Bunt, R. Sakurovs and J. P. Mathews, Fuel, 2015, 158, 779-792.

22 G. Levi, O. Senneca, M. Causà, P. Salatino, P. Lacovig and S. Lizzit, Carbon, 2015, 90, 181-196.

23 W. Xia, J. Yang and C. Liang, Appl. Surf. Sci., 2014, 293, 293298.

24 S. Murata, M. Hosokawa, K. Kidena and M. Nomura, Fuel Process. Technol., 2000, 67, 231-243.

25 O. Yamamoto, K. Hayamizu, M. Yanagisawa, A. Yabe and Y. Sugimoto, J. Jpn. Inst. Energy, 1994, 73, 267-278.

26 W. M. Cheng, C. C. Xu and G. Zhou, J. Fuel Chem. Technol., 2016, 44, 295-304, in Chinese.

27 G. Wang, W. X. Li, P. F. Wang, X. X. Yang and S. T. Zhang, Int. J. Rock Mech. Min., 2017, 91, 72-80.

28 Q. G. Yao, C. C. Xu, Y. S. Zhang, G. Zhou, S. C. Zhang and D. Wang, Process Saf. Environ. Prot., 2017, 111, 726-732.

29 G. Zhou, W. M. Cheng, C. C. Xu and W. Nie, J. China Coal Soc., 2015, 40, 2849-2855, in Chinese.

30 M. Kozłowski, Fuel, 2004, 83, 259-265.

31 J. Wang, J. Du, L. Chang and K. Xie, Fuel Process. Technol., 2010, 91, 430-433.

32 Y. Qin, J. Bo and D. Y. Song, J. China Coal Soc., 1998, 23, 634638.

33 W. M. Cheng, X. M. Hu, J. Xie and Y. Y. Zhao, Fuel, 2017, 210, 826-835. 